\title{
Prognostic performance of different lymph node classification systems in young gastric cancer
}

\author{
Yi-Ru Chen ${ }^{1 \#} \wedge$, Mei-Qian Wang ${ }^{1 \#}$, Yi-Ting Li $^{2 \#}$, Ping Li ${ }^{1}$, Su-Shan Ouyang ${ }^{1}$, Hui-Wen Xu ${ }^{1}$, Sen-Lin Zhu ${ }^{1}$ \\ ${ }^{1}$ Department of Gastroenterology and Hepatology, The First Affiliated Hospital of Sun Yat-sen University, Guangzhou, China; ${ }^{2}$ Department of \\ General Practice, The Third Affiliated Hospital of Sun Yat-sen University, Guangzhou, China \\ Contributions: (I) Conception and design: YR Chen, MQ Wang, YT Li, SL Zhu; (II) Administrative support: SL Zhu; (III) Provision of study \\ materials or patients: YR Chen, MQ Wang, YT Li; (IV) Collection and assembly of data: P Li, SS Ouyang, HW Xu; (V) Data analysis and \\ interpretation: YR Chen, MQ Wang, YT Li; (VI) Manuscript writing: All authors; (VII) Final approval of manuscript: All authors. \\ \#These authors contributed equally to this work. \\ Correspondence to: Sen-Lin Zhu. The First Affiliated Hospital of Sun Yat-sen University, 58 Zhongshan 2nd Road, Guangzhou 510080, China. \\ Email: zhusl@mail.sysu.edu.cn.
}

Background: Accurate staging plays a pivotal role in cancer care. The lymph node (LN) ratio (LNR) and the $\log$ odds of positive LNs (LODDS) have been suggested as alternatives to the N staging since the TNM system has the risk of stage migration. The prognostic significance of LNR and LODDS in young patients with gastric cancer (GC) has not been reported. This study aims to investigate the correlations between LNR and LODDS and survival of young patients with GC, and compare the predictive performance of these LN staging methods.

Methods: GC patients before the age of 40 from 2004 to 2016 in the Surveillance, Epidemiology and End Results database were enrolled. The prognostic evaluation of the $\mathrm{N}$ factor, LNR and LODDS was compared using the time-dependent receiver operating characteristic (ROC) analysis, area under the curve (AUC), C-index and Akaike information criterion (AIC).

Results: Multivariate survival analysis identified that the LNR and LODDS were significantly independent prognostic indicators for overall survival (OS) in young patients with GC and in the subgroups comprised of patients with $\leq 15$ LNs examined. The time-dependent ROC curves of the LNR and LODDS were continuously superior to that of the $\mathrm{N}$ factor in predicting OS during the observation period. And the AUCs revealed that the predictive accuracy of the LNR and LODDS was remarkably superior to the $\mathrm{N}$ factor at 1 and 3 years $(\mathrm{P}<0.05)$. The model incorporating LNR or LODDS had higher $\mathrm{C}$-index and lower AIC when comparing to the model incorporating the $\mathrm{N}$ factor.

Conclusions: The LNR and LODDS improve accuracy of survival risk prediction in young patients with GC when comparing to the $\mathrm{N}$ factor. These two novel LN classification methods should be considered as alternatives to the $\mathrm{N}$ staging for the prognostic prediction of young patients with GC.

Keywords: Young patients; gastric cancer (GC); lymph node ratio (LNR); log odds of positive lymph nodes; prognosis

Submitted Apr 05, 2021. Accepted for publication Jun 30, 2021.

doi: 10.21037/jgo-21-185

View this article at: https://dx.doi.org/10.21037/jgo-21-185

^ ORCID: 0000-0001-6202-740X. 


\section{Introduction}

Gastric cancer (GC) ranks as the fifth most frequent malignancy worldwide, and is the fourth main cause of cancerrelated deaths (1). GC is generally considered to be an agerelated disease. Although most GC patients are middle-aged and elderly, there has been reported a rising trend recently in young cases $(2,3)$. The definitions of GC in young patients were quite inconsistent among studies. Most literatures defined young age as below 40 (4-7) or 45 years (8-10), while others used $30(11,12), 50(13,14), 60(15)$ or even $70(16)$. With different age criterion used, young subjects accounted for $2-31 \%$ of all GC cases (10,17-19). Accumulating studies have found that young patients with GC tended to have higher rates of female sex, and were more prone to have aggressive biological features, including diffuse or signetring histology, poorly differentiated lesions, advanced tumor stage, and frequent nodal involvement (6,9,20-22). Despite a favorable general condition, organ function and tolerance to treatment in young GC patients, a large proportion of them may have no alarm symptoms, contributing to delay in diagnosis and a poor clinical outcome. Young patients with GC face unique challenges including differences in tumor biological characteristics and variations in effectiveness and safety of treatment $(9,23,24)$. Meanwhile, considerations about fertility preservation and early death need to be taken into in such special population. Thus, an effective and practical scoring system for accurate prognostic prediction and optimal treatment is of vital significance with respect to these patients.

Accurate staging plays a pivotal role in cancer care. It could reflect the extent of tumors, determine treatment options, predict prognosis, and enable different countries and institutions to compare patient cohorts. Currently, the American Joint Committee on Cancer (AJCC) TNM staging is the universally accepted system in cancer, which is based on the depth of the primary tumor invasion ( $T$ stage), the number of metastatic lymph nodes ( $\mathrm{N}$ stage) and the status of distant metastasis (M stage) (25-27). However, the current existing TNM staging is subject to the risk of stage migration when using the N category (26,28-31). Stage migration, so-called Will Rogers phenomenon, refers to instances in which judgement of an insufficient count of lymph nodes (LNs) removed results in understaging and subsequent underestimation of disease severity (32). In GC, the AJCC staging system recommends that at least $15 \mathrm{LNs}$ should be examined for an accurate estimation of $\mathrm{N}$ stage (26). To minimize the bias caused by an insufficient count of harvested LNs and stage migration, the lymph node ratio (LNR) (33-39) and the log odds of positive
LNs (LODDS) have been proposed $(40,41)$. The former is calculated by dividing the count of metastatic LNs by the sum of examined LNs, while the latter is defined as the logarithm of the ratio between positive nodes and negative nodes. Extensive studies have reported superior predictive values of the LNR and LODDS when compared with the present $\mathrm{N}$ stage using only a metastatic $\mathrm{LN}$ count, and considered these two novel $\mathrm{LN}$ staging methods as alternatives to the $\mathrm{N}$ stage (33-41). However, findings for the role of the LNR and LODDS in young patients with GC have not been reported.

The Surveillance, Epidemiology, and End Results (SEER) database is an US National Cancer Institute's openaccess public database with an annual update. It captures a wide variety of demographic and clinical data as well as data on treatment and survival from 18 established cancer registries covering about $34.6 \%$ of the US population. In this study, we aimed to investigate the correlations between different LN classification methods (AJCC N stage, LNR and LODDS) and survival of young patients with GC, and compare the predictive performance of these three $\mathrm{LN}$ staging methods through reviewing data obtained from the SEER dataset.

We present the following article in accordance with the STROBE reporting checklist (available at https://dx.doi. org/10.21037/jgo-21-185).

\section{Methods}

\section{Study population}

Our design was a population-based and retrospective study. In this study, GC in young patients was defined as that manifesting before 40 years old, as was indicated by previous studies (4-7). From 2004 to 2016, young patients with GC patients who were histologically proven diagnosed were included. We used the International Classification of Diseases for Oncology, 3rd Edition (ICD-O-3) to determine the tumor sites (C16.0-C16.6, C16.8, C16.9) and histological types (8010-8231, 8255-8576). The exclusion criteria were the following: (I) patients with record of previous malignant disease before being diagnosed with GC; (II) patients without histopathologic diagnosis or diagnosed only at autopsy or via death certificate; (III) patients without important clinicopathological information (tumor size $=0$ or $\mathrm{T}$ stage $=\mathrm{T} 0 / \mathrm{blank}$ ); (IV) patients with incomplete or inaccessible follow-up; (V) unknown surgery information or patients without surgery; (VI) zero or unknown examined lymph nodes; (VII) unknown positive lymph nodes; (VIII) 


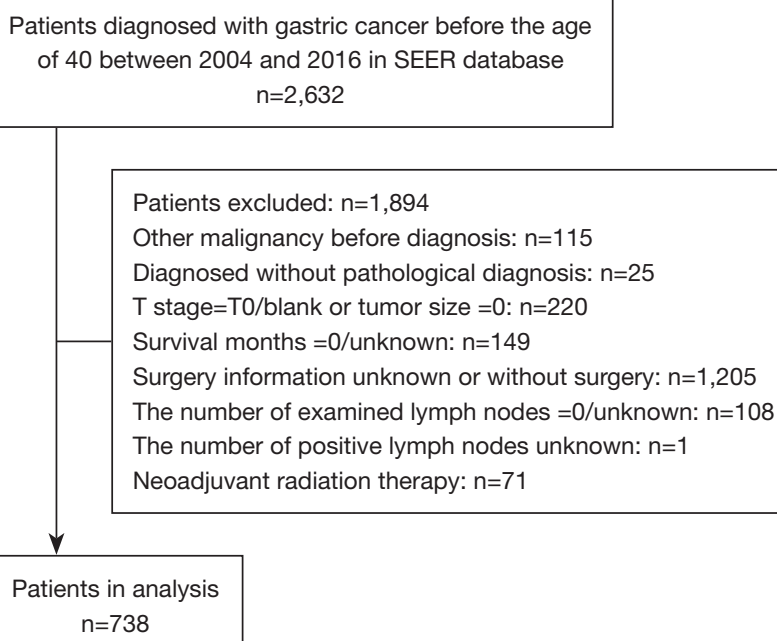

Figure 1 Flowchart for selection procedure of young patients with gastric cancer from Surveillance, Epidemiology and End Results (SEER) database.

patients with neoadjuvant radiation therapy. SEER*Stat software version 8.3.8 (https://www.seer.cancer.gov/seerstat) was applied to extract the data and construct the case listing. A total of 738 patients were included in the study. Figure 1 showed the detailed workflow process for patient selection. The SEER database is an open-access cancer database that only contains de-identified patient data. Therefore, this study was exempted from the approval by the institutional review board of the First Affiliated Hospital of Sun Yat-sen University.

For each patient, the demographic characteristics (including age at diagnosis, race, gender, marital status and insurance), tumor and treatment features (including tumor location, grade, histology type, tumor size, the number of examined LNs, T stage, $\mathrm{N}$ stage, $\mathrm{M}$ stage, surgery, chemotherapy, and radiotherapy), and follow-up information (including survival status, survival time and cause of death) were acquired. Primary tumor sites in this study were classified into four categories: cardia (C16.0), middle site (C16.1, C16.2, C16.5, C16.6), distal site (C16.3, C16.4), as well as overlapping or not otherwise specified (NOS) (C16.8, C16.9). We divided histology types into three categories: diffuse type $(8020,8021,8022,8142,8145$, $8490)$, intestinal type $(8140,8144,8210,8211,8260,8480$, $8481)$, and other type $(8010,8032,8033,8041,8071,8255$, $8560,8576)$. The final follow-up evaluation was conducted in December 31, 2016. The outcome in this study was overall survival (OS), defined as the period from the time of initial diagnosis to the time of death from any cause or survive at last follow-up.

\section{Definition of lymph node ratio and log odds of positive lymph nodes}

The LNR was calculated by dividing the count of positive LNs by the sum of corresponding examined LNs in the SEER database. The LODDS was defined as $\log _{10}$ [(positive $\mathrm{LNs}+0.5) /($ negative $\mathrm{LNs}+0.5)]$. We added 0.5 to both the denominator and the numerator to avoid singularity. Although the SEER program recorded the types of gastrectomy performed on some patients, such as total or subtotal/partial gastrectomy, there were still quite a few cases without detailed types of gastric resection. What we could obtain from the SEER was the sum of lymph nodes which were removed and examined by the pathologist (the examined LNs), as well as the exact number of lymph nodes that had metastasized (the positive LNs). In this study, the optimal cutoff levels for LNR and LODDS were 0.36 and -0.28 , respectively, which were derived using $\mathrm{X}$-tile software (Yale University, New Haven, CT, USA) (42). All the patients were further categorized into the pathologically negative lymph node metastasis group (N0, pN-) and pathologically positive lymph node metastasis group $(\mathrm{N} 1-3, \mathrm{pN}+)$, the low LNR $(\leq 0.36, \mathrm{~L}-\mathrm{LNR})$ group and the high LNR $(>0.36, \mathrm{H}-\mathrm{LNR})$ group, the low LODDS $(\leq-0.28, \mathrm{~L}-\mathrm{LODDS})$ group and the high LODDS $(>-0.28$, H-LODDS) group.

\section{Statistical analysis}

Continuous variables were presented as medians and interquartile ranges (IQR), while categorical variables were presented as the number and the percentage $(\mathrm{N}, \%)$. Correlations between continuous variables were assessed via the Kruskal-Wallis analysis, and categorical variables were analyzed using the Chi-square or Fisher's exact test. Survival curves were plotted using Kaplan-Meier method and analyzed by log-rank test. Univariate and multivariate survival analyses were conducted using the Cox proportional hazards regression model. The hazard ratios (HRs) and 95\% confidence intervals (CIs) were shown. Variables that obviously influenced survival in univariate analysis were entered into multivariate analysis to identify prognostic indicators. The predictive performance of AJCC N factor, LNR and LODDS were assessed by time-dependent receiver operating characteristic (ROC) curves $(43,44)$ and 
area under the curve (AUC). The Harrell's concordance index (C-index) and Akaike information criterion (AIC) were calculated to identify the predictive accuracy and discriminating superiority of different multivariate prediction models incorporating AJCC $\mathrm{N}$ factor, LNR and LODDS, respectively. A higher C-index and a lower AIC indicated a better predictive accuracy. Statistical analyses were performed using SPSS software version 20.0 (Chicago, IL, USA) and R software version 3.6.1 (https://www. r-project.org/). All analyses were two-tailed, and statistical significant levels were set at $\mathrm{P}$-value $<0.05$.

The study was conducted in accordance with the Declaration of Helsinki (as revised in 2013).

\section{Results}

\section{Clinicopatbological characteristics}

Totally, 738 young patients with pathologically confirmed GC were eligible for the final analysis. The median age of the all cases was 36 years (IQR: $32-39$ years), $47.7 \%$ of the patients were men $(\mathrm{N}=352), 52.3 \%$ were women $(\mathrm{N}=386)$. Caucasians accounted for a large proportion of the cohort $(65.1 \%, \mathrm{~N}=480)$, and more than half of patients were married $(59.0 \%, \mathrm{~N}=435) .80 .7 \%$ of the tumors were poorly differentiated ( $\mathrm{N}=595)$, and the most common histology type was diffuse $(59.2 \%, \mathrm{~N}=437)$. The median number of examined LNs was 17 (IQR: $11-27 \mathrm{LNs}$ ), $43.5 \%$ of the patients were with 15 or fewer examined LNs $(\mathrm{N}=321)$, $56.5 \%$ were with 16 or more examined LNs $(\mathrm{N}=417)$. Table 1 showed the demographic and clinicopathological features of the study cohort.

\section{Clinicopathological findings}

The correlations between clinicopathological factors and the AJCC N factor, LNR, and LODDS were listed in Table 1. There were 207 patients $(28.0 \%)$ in the $\mathrm{pN}$ - group and 531 patients $(72.0 \%)$ in the $\mathrm{pN}+$ group, 452 patients $(61.2 \%)$ in the L-LNR group and 286 (38.8\%) patients in the H-LNR group, 442 patients $(59.9 \%)$ in the L-LODDS group and 296 patients $(40.1 \%)$ in the H-LODDS group. The positive LN metastasis and increased LNR and LODDS were significantly correlated with insurance $(\mathrm{P}=0.006, \mathrm{P}=0.001$, $\mathrm{P}=0.001)$, a higher degree of differentiated type $(\mathrm{P}<0.001$, $\mathrm{P}=0.047, \mathrm{P}=0.022$ ), a larger tumor size (all $\mathrm{P}<0.001$ ), an advanced $\mathrm{T}$ stage (all $\mathrm{P}<0.001$ ), distant metastasis (all $\mathrm{P}<0.001)$, and administration of chemotherapy $(\mathrm{P}<0.001$,
$\mathrm{P}=0.001, \mathrm{P}=0.001)$. The positive $\mathrm{LN}$ metastasis showed a significant correlation with the marital status $(\mathrm{P}=0.004)$ and administration of radiotherapy $(\mathrm{P}<0.001)$. The increased LNR and LODDS were correlated with tumor subsites $(\mathrm{P}<0.001, \mathrm{P}=0.002)$.

The positive LN metastasis was correlated with a higher number of total LNs examined $(\mathrm{P}<0.001)$, while the increased LNR and LODDS showed significant correlations with a lower number of total LNs examined $(\mathrm{P}=0.001, \mathrm{P}=0.001)$. Furthermore, the AJCC $\mathrm{N}$ factor showed a significant correlation $(\mathrm{P}<0.001)$ when the all patients were divided into either the $\leq 15$ total LNs group or the $>15$ total LNs group, yet LNR and LODDS showed no remarkable differences.

\section{Survival analysis}

The median survival time was 29 months, while that of the quartile was $12-68$ months. Among the 738 young patients with GC, 403 (54.6\%) succumbed to all causes of death, including 380 patients $(51.5 \%)$ who had cancer-specific death and $23(3.1 \%)$ who died from non-cancer-related causes.

The influences of the three different LN staging methods on OS of the study cohort were presented in Figure 2 using the Kaplan-Meier method. The 5-year OS rates for $\mathrm{pN}$ group were $0.769,0.305$ for $\mathrm{pN}+$ group, with a remarkable distinction $(\mathrm{P}<0.001)$ (Figure $2 A)$. The 5 -year $\mathrm{OS}$ rates for L-LNR group were $0.598,0.179$ for H-LNR group, with a statistical difference $(\mathrm{P}<0.001)$ (Figure $2 B)$. Similarly, the 5 -year OS rates for L-LODDS group were $0.613,0.175$ for H-LODDS group, with a statistically prominent difference $(\mathrm{P}<0.001)$ (Figure 2C).

Univariate survival analysis identified a series of factors including the race, tumor subsites, tumor size, $\mathrm{T}$ stage, AJCC $\mathrm{N}$ factor, LNR, LODDS, $M$ stage, together with chemotherapy to be predictors for OS (Table 2). The variables that remarkably influenced survival in univariate analysis were investigated using the Cox regression model for multivariate analysis. Multivariate analysis demonstrated that the $\mathrm{N}$ factor $(\mathrm{HR}=1.766,95 \% \mathrm{CI}: 1.274-2.449$, $\mathrm{P}=0.001)$, LNR (HR $=1.886,95 \%$ CI: $1.518-2.342$, $\mathrm{P}<0.001)$ and LODDS (HR $=1.939,95 \%$ CI: $1.559-2.410$, $\mathrm{P}<0.001)$ were independent prognostic indicators.

\section{Time-dependent ROC curve analysis}

The time-dependent ROC curves were constructed to 
Table 1 Patients' clinicopathological characteristics and associations with the AJCC N factor, LNR and LODDS

\begin{tabular}{|c|c|c|c|c|c|c|c|c|c|c|}
\hline Characteristics & All case & \multicolumn{3}{|c|}{ AJCC $\mathrm{N}$ factor } & \multicolumn{3}{|c|}{ LNR } & \multicolumn{3}{|c|}{ LODDS } \\
\hline Cases & 738 & 207 & 531 & & 452 & 286 & & 442 & 296 & \\
\hline \multicolumn{11}{|l|}{ Age } \\
\hline Median (IQR) & $36(32-39)$ & 36 (32-39) & $36(32-38)$ & 0.553 & $36(32-39)$ & $36(32-38)$ & 0.213 & 36 (32-39) & $36(32-38.8)$ & 0.203 \\
\hline White & $480(65.1)$ & 129 (62.3) & $351(66.1)$ & 0.368 & $288(63.7)$ & $192(67.1)$ & 0.573 & $284(64.3)$ & 196 (66.2) & 0.684 \\
\hline Black & $94(12.7)$ & $32(15.5)$ & $62(11.7)$ & & $58(12.8)$ & 36 (12.6) & & 55 (12.4) & 39 (13.2) & \\
\hline Others $^{\dagger} /$ NOS & 164 (22.2) & $46(22.2)$ & 118 (22.2) & & $106(23.5)$ & $58(20.3)$ & & 103 (23.3) & $61(20.6)$ & \\
\hline \multicolumn{11}{|l|}{ Gender } \\
\hline \multicolumn{11}{|l|}{ Insurance } \\
\hline Yes & 481 (65.2) & 151 (72.9) & $330(62.1)$ & $0.006^{\star}$ & $320(70.8)$ & $161(56.3)$ & $<0.001^{*}$ & $316(71.5)$ & $165(55.7)$ & $<0.001^{\star}$ \\
\hline No/unknown & 257 (34.8) & $56(27.1)$ & 201 (37.9) & & 132 (29.2) & $125(43.7)$ & & $126(28.5)$ & $131(44.3)$ & \\
\hline \multicolumn{11}{|l|}{ Marital status } \\
\hline Married & 435 (59.0) & 107 (51.7) & $328(61.8)$ & $0.004^{\star}$ & $262(58.0)$ & $173(60.5)$ & 0.825 & $258(58.4)$ & $177(59.8)$ & 0.969 \\
\hline Single & 246 (33.3) & 75 (36.2) & 171 (32.2) & & 155 (34.3) & $91(31.9)$ & & 150 (33.9) & $96(32.4)$ & \\
\hline $\begin{array}{l}\text { Separated/divorced/ } \\
\text { widowed }\end{array}$ & $36(4.9)$ & $13(6.3)$ & $23(4.3)$ & & $21(4.6)$ & $15(5.2)$ & & $21(4.8)$ & $15(5.1)$ & \\
\hline Overlapping/NOS & $167(22.6)$ & $39(18.8)$ & $128(24.1)$ & & $79(17.5)$ & $88(30.8)$ & & 79 (17.9) & $88(29.7)$ & \\
\hline \multicolumn{11}{|l|}{ Differentiation } \\
\hline Well differentiated & $9(1.2)$ & $6(2.9)$ & $3(0.6)$ & $<0.001^{*}$ & $9(2.0)$ & 0 & $0.047^{*}$ & $9(2.0)$ & 0 & $0.022^{*}$ \\
\hline $\begin{array}{l}\text { Moderately } \\
\text { differentiated }\end{array}$ & $71(9.6)$ & $26(12.6)$ & $45(8.4)$ & & $50(11.1)$ & $21(7.3)$ & & $50(11.3)$ & $21(7.1)$ & \\
\hline Poorly differentiated & $595(80.7)$ & $149(72.0)$ & $446(84.0)$ & & $355(78.5)$ & $240(83.9)$ & & $346(78.3)$ & $249(84.1)$ & \\
\hline Undifferentiated & $26(3.5)$ & $5(2.4)$ & $21(4.0)$ & & $14(3.1)$ & $12(4.2)$ & & $13(3.0)$ & $13(4.4)$ & \\
\hline Unknown & $37(5.0)$ & $21(10.1)$ & $16(3.0)$ & & $24(5.3)$ & $13(4.6)$ & & $24(5.4)$ & $13(4.4)$ & \\
\hline \multicolumn{11}{|l|}{ Histological type } \\
\hline Diffuse & 437 (59.2) & $131(63.3)$ & $306(57.6)$ & 0.217 & $267(59.1)$ & $170(59.4)$ & 0.611 & $260(58.8)$ & $177(59.8)$ & 0.673 \\
\hline Intestinal & $264(35.8)$ & $64(30.9)$ & $200(37.7)$ & & $165(36.5)$ & 99 (34.6) & & $162(36.7)$ & $102(34.5)$ & \\
\hline Other & $37(5.0)$ & $12(5.8)$ & $25(4.7)$ & & $20(4.4)$ & $17(6.0)$ & & $20(4.5)$ & $17(5.7)$ & \\
\hline
\end{tabular}

Table 1 (continued) 
Table 1 (continued)

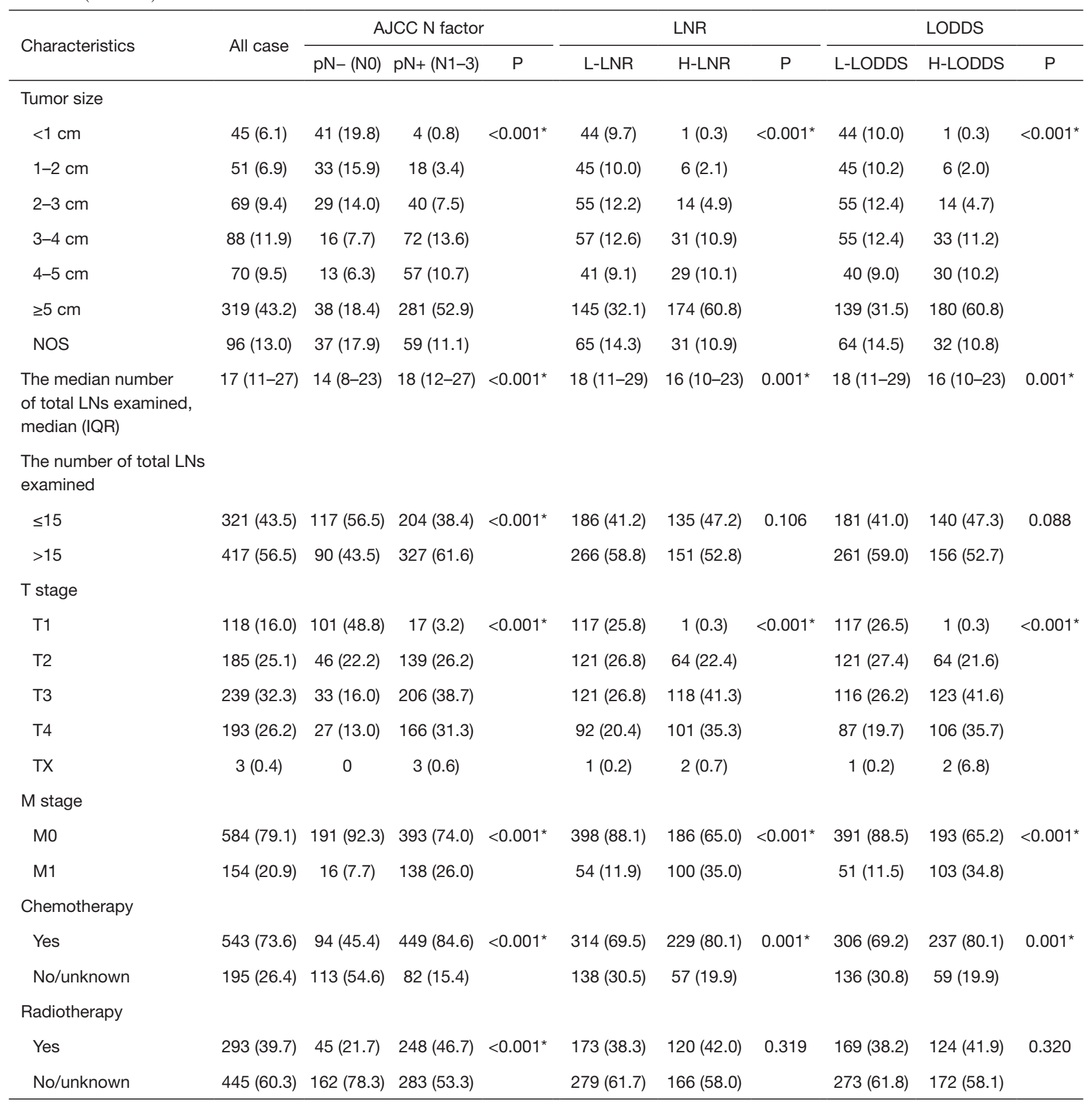

LNR, lymph node ratio; LODDS, the log odds of positive lymph nodes; NOS, not otherwise specified; LN, lymph node. *, indicate significant $P$ values. ${ }^{\dagger}$, Others, American Indian/AK Native, Asian/Pacific Islander. 
A

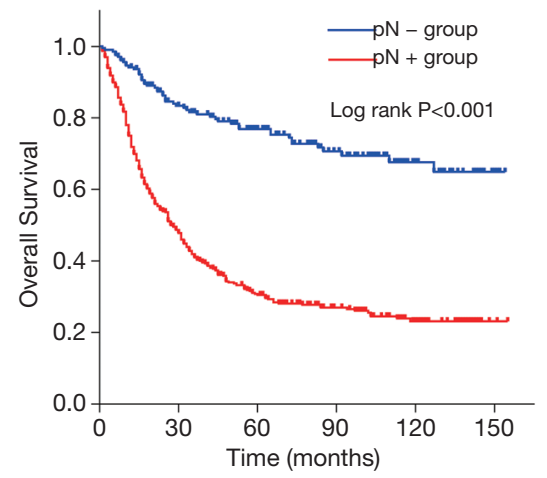

B

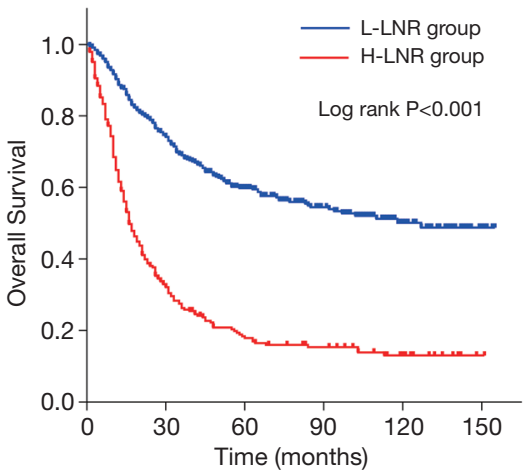

C

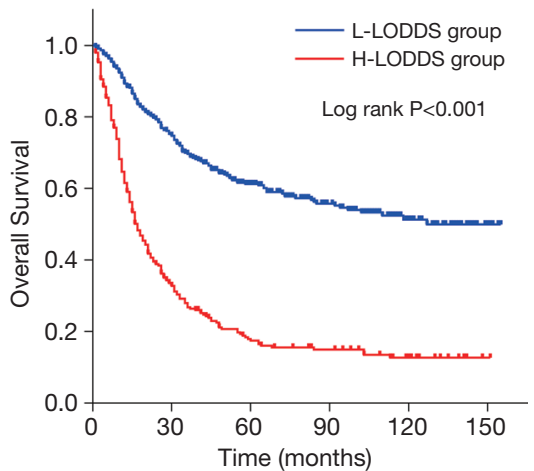

Figure 2 Kaplan-Meier analysis for overall survival of young gastric cancer patients in the negative and positive lymph node metastasis groups (A), low and high lymph node ratio groups (B), and low and high log odds of positive lymph nodes groups (C). The AJCC N factor, LNR and LODDS were significantly associated with overall survival (all $\mathrm{P}<0.001$ ). LNR, lymph node ratio; LODDS, log odds of positive lymph nodes.

Table 2 Univariate and multivariate Cox proportional hazards regression analyses for OS

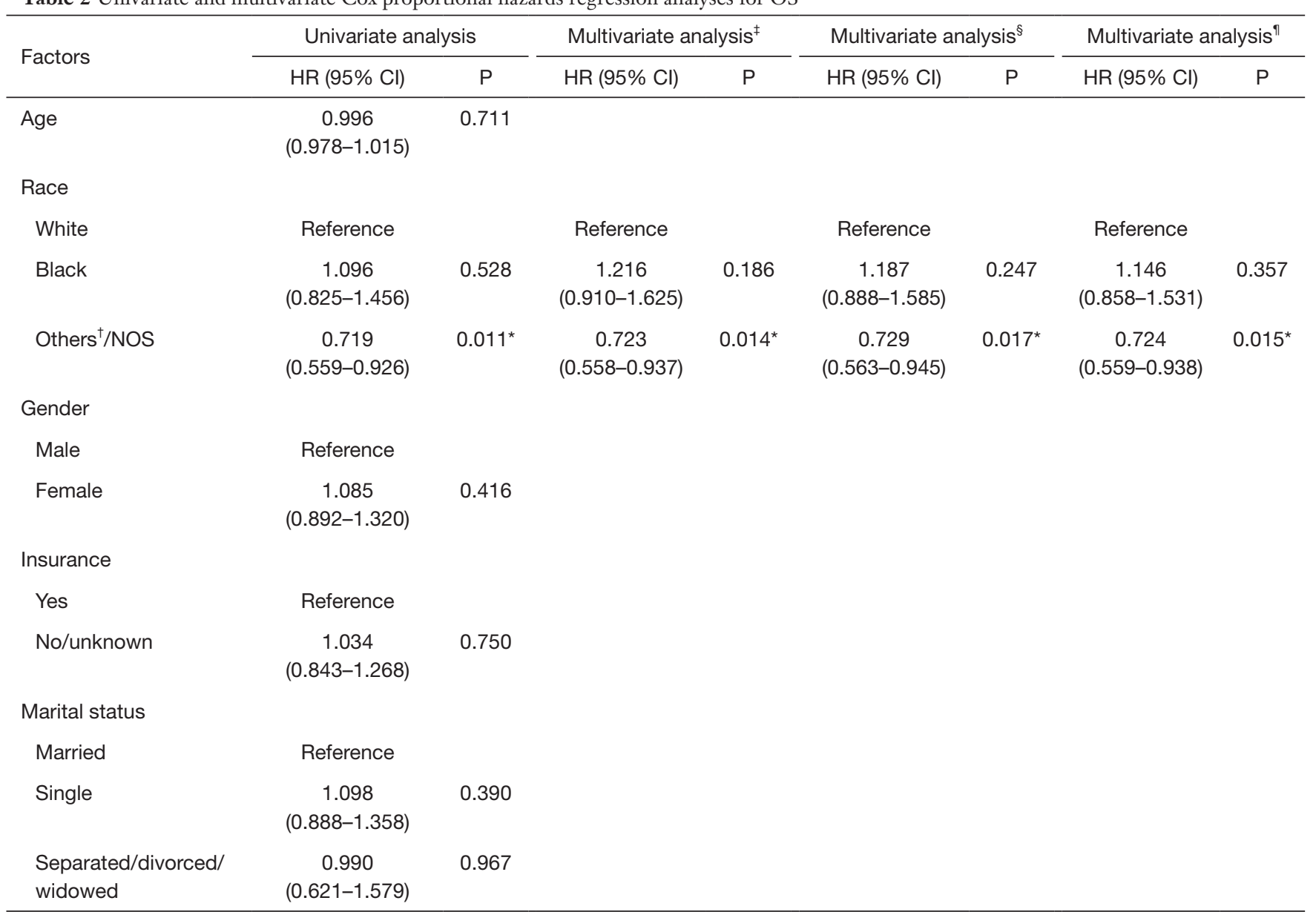

Table 2 (continued) 
Table 2 (continued)

\begin{tabular}{|c|c|c|c|c|c|c|c|c|}
\hline Factors & \multicolumn{2}{|c|}{ Univariate analysis } & \multicolumn{2}{|c|}{ Multivariate analysis ${ }^{\ddagger}$} & \multicolumn{2}{|c|}{ Multivariate analysis ${ }^{\S}$} & \multicolumn{2}{|c|}{ Multivariate analysis" } \\
\hline NOS & $\begin{array}{c}0.636 \\
(0.300-1.348)\end{array}$ & 0.238 & & & & & & \\
\hline \multicolumn{9}{|l|}{ Tumor subsites } \\
\hline Cardia & Reference & & Reference & & Reference & & Reference & \\
\hline Distal & $\begin{array}{c}0.943 \\
(0.694-1.281)\end{array}$ & 0.705 & $\begin{array}{c}0.786 \\
(0.571-1.081)\end{array}$ & 0.139 & $\begin{array}{c}0.759 \\
(0.553-1.042)\end{array}$ & 0.088 & $\begin{array}{c}0.755 \\
(0.550-1.038)\end{array}$ & 0.083 \\
\hline Overlapping/NOS & $\begin{array}{c}1.649 \\
(1.207-2.253)\end{array}$ & $0.002^{*}$ & $\begin{array}{c}1.101 \\
(0.790-1.535)\end{array}$ & 0.569 & $\begin{array}{c}0.944 \\
(0.676-1.319)\end{array}$ & 0.736 & $\begin{array}{c}0.948 \\
(0.679-1.324)\end{array}$ & 0.753 \\
\hline \multicolumn{9}{|l|}{ Differentiation } \\
\hline $\begin{array}{l}\text { Moderately } \\
\text { differentiated }\end{array}$ & $\begin{array}{c}2.045 \\
(0.491-8.524)\end{array}$ & 0.326 & & & & & & \\
\hline Poorly differentiated & $\begin{array}{c}3.006 \\
(0.749-12.073)\end{array}$ & 0.121 & & & & & & \\
\hline Undifferentiated & $\begin{array}{c}3.854 \\
(0.885-16.772)\end{array}$ & 0.072 & & & & & & \\
\hline Unknown & $\begin{array}{c}2.077 \\
(0.480-8.993)\end{array}$ & 0.328 & & & & & & \\
\hline \multicolumn{9}{|l|}{ Histological type } \\
\hline \multicolumn{9}{|l|}{ Tumor size } \\
\hline$<1 \mathrm{~cm}$ & Reference & & Reference & & Reference & & Reference & \\
\hline $1-2 \mathrm{~cm}$ & $\begin{array}{c}2.170 \\
(0.834-5.647)\end{array}$ & 0.112 & $\begin{array}{c}0.934 \\
(0.343-2.547)\end{array}$ & 0.894 & $\begin{array}{c}1.041 \\
(0.382-2.833)\end{array}$ & 0.938 & $\begin{array}{c}1.044 \\
(0.383-2.844)\end{array}$ & 0.933 \\
\hline $2-3 \mathrm{~cm}$ & $\begin{array}{c}2.631 \\
(1.062-6.520)\end{array}$ & $0.037^{\star}$ & $\begin{array}{c}0.646 \\
(0.241-1.733)\end{array}$ & 0.386 & $\begin{array}{c}0.650 \\
(0.242-1.745)\end{array}$ & 0.392 & $\begin{array}{c}0.649 \\
(0.241-1.746)\end{array}$ & 0.392 \\
\hline $3-4 \mathrm{~cm}$ & $\begin{array}{c}4.822 \\
(2.052-11.330)\end{array}$ & $<0.001^{*}$ & $\begin{array}{c}0.687 \\
(0.265-1.780)\end{array}$ & 0.440 & $\begin{array}{c}0.705 \\
(0.272-1.824)\end{array}$ & 0.471 & $\begin{array}{c}0.687 \\
(0.265-1.780)\end{array}$ & 0.440 \\
\hline $4-5 \mathrm{~cm}$ & $\begin{array}{c}7.529 \\
(3.206-17.679)\end{array}$ & $<0.001^{*}$ & $\begin{array}{c}1.060 \\
(0.410-2.740)\end{array}$ & 0.905 & $\begin{array}{c}1.078 \\
(0.416-2.790)\end{array}$ & 0.877 & $\begin{array}{c}1.051 \\
(0.405-2.727)\end{array}$ & 0.918 \\
\hline$\geq 5 \mathrm{~cm}$ & $\begin{array}{c}8.387 \\
(3.725-18.885)\end{array}$ & $<0.001^{*}$ & $\begin{array}{c}1.006 \\
(0.403-2.513)\end{array}$ & 0.989 & $\begin{array}{c}1.017 \\
(0.408-2.537)\end{array}$ & 0.971 & $\begin{array}{c}0.998 \\
(0.399-2.494)\end{array}$ & 0.997 \\
\hline
\end{tabular}

Table 2 (continued) 
Table 2 (continued)

\begin{tabular}{|c|c|c|c|c|c|c|c|c|}
\hline Factors & \multicolumn{2}{|c|}{ Univariate analysis } & \multicolumn{2}{|c|}{ Multivariate analysis ${ }^{\ddagger}$} & \multicolumn{2}{|c|}{ Multivariate analysis $\$$} & \multicolumn{2}{|c|}{ Multivariate analysis" } \\
\hline NOS & $\begin{array}{c}6.196 \\
(2.665-14.406)\end{array}$ & $<0.001^{*}$ & $\begin{array}{c}1.034 \\
(0.407-2.628)\end{array}$ & 0.943 & $\begin{array}{c}1.091 \\
(0.429-2.776)\end{array}$ & 0.855 & $\begin{array}{c}1.080 \\
(0.424-2.751)\end{array}$ & 0.872 \\
\hline \multicolumn{9}{|l|}{ T stage } \\
\hline $\mathrm{T} 1$ & Reference & & Reference & & Reference & & Reference & \\
\hline T3 & $\begin{array}{c}14.762 \\
(7.519-28.982)\end{array}$ & $<0.001^{*}$ & $\begin{array}{c}11.888 \\
(5.329-26.519)\end{array}$ & $<0.001^{*}$ & $\begin{array}{c}13.315 \\
(6.014-29.480)\end{array}$ & $<0.001^{*}$ & $\begin{array}{c}13.022 \\
(5.873-28.872)\end{array}$ & $<0.001^{*}$ \\
\hline $\mathrm{T} 4$ & $\begin{array}{c}23.486 \\
(11.928-46.243)\end{array}$ & $<0.001^{*}$ & $\begin{array}{c}17.319 \\
(7.733-38.784)\end{array}$ & $<0.001^{*}$ & $\begin{array}{c}20.507 \\
(9.229-45.565)\end{array}$ & $<0.001^{*}$ & $\begin{array}{c}20.042 \\
(9.005-44.609)\end{array}$ & $<0.001^{*}$ \\
\hline \multicolumn{9}{|l|}{ AJCC N factor } \\
\hline No & Reference & & Reference & & Not applicable & & Not applicable & \\
\hline N1-3 & $\begin{array}{c}3.942 \\
(2.942-5.281)\end{array}$ & $<0.001^{*}$ & $\begin{array}{c}1.766 \\
(1.274-2.449)\end{array}$ & $0.001^{*}$ & & & & \\
\hline LNR & & & Not applicable & & & & Not applicable & \\
\hline L-LNR & Reference & & & & Reference & & & \\
\hline H-LNR & $\begin{array}{c}3.350 \\
(2.744-4.088)\end{array}$ & $<0.001^{*}$ & & & $\begin{array}{c}1.886 \\
(1.518-2.342)\end{array}$ & $<0.001^{*}$ & & \\
\hline LODDS & & & Not applicable & & Not applicable & & & \\
\hline M1 & $\begin{array}{c}3.929 \\
(3.177-4.860)\end{array}$ & $<0.001^{*}$ & $\begin{array}{c}2.681 \\
(2.144-3.351)\end{array}$ & $<0.001^{*}$ & $\begin{array}{c}2.477 \\
(1.973-3.111)\end{array}$ & $<0.001^{*}$ & $\begin{array}{c}2.485 \\
(1.979-3.119)\end{array}$ & $<0.001^{*}$ \\
\hline \multicolumn{9}{|l|}{ Chemotherapy } \\
\hline Yes & Reference & & Reference & & Reference & & Reference & \\
\hline No/unknown & $\begin{array}{c}0.666 \\
(0.522-0.850)\end{array}$ & $0.001^{*}$ & $\begin{array}{c}1.684 \\
(1.303-2.178)\end{array}$ & $<0.001^{*}$ & $\begin{array}{c}1.598 \\
(1.236-2.065)\end{array}$ & $<0.001^{*}$ & $\begin{array}{c}1.587 \\
(1.227-2.051)\end{array}$ & $<0.001^{*}$ \\
\hline \multicolumn{9}{|l|}{ Radiotherapy } \\
\hline Yes & Reference & & & & & & & \\
\hline No/unknown & $\begin{array}{c}1.105 \\
(0.905-1.348)\end{array}$ & 0.328 & & & & & & \\
\hline
\end{tabular}

LNR, Iymph node ratio; LODDS, the log odds of positive lymph nodes; NOS, not otherwise specified; HR, hazard ratio; Cl, confidence interval. * indicate significant $P$ values. ${ }^{\dagger}$, Others, American Indian/AK Native, Asian/Pacific Islander. ${ }^{\ddagger}$, Adjustment for the following variables: race, tumor subsites, tumor size, T stage, $\mathrm{N}$ stage, M stage, and chemotherapy. ${ }^{\S}$, Adjustment for the following variables: race, tumor subsites, tumor size, T stage, LNR, M stage, and chemotherapy. ", Adjustment for the following variables: race, tumor subsites, tumor size, T stage, LODDS, M stage, and chemotherapy. 
A

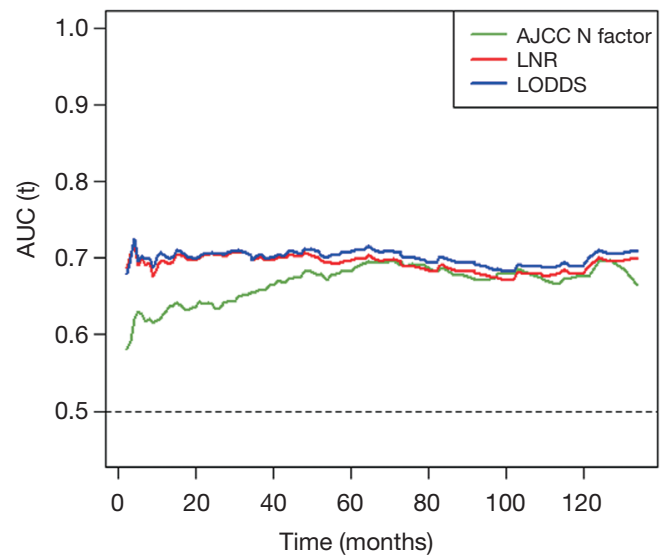

B

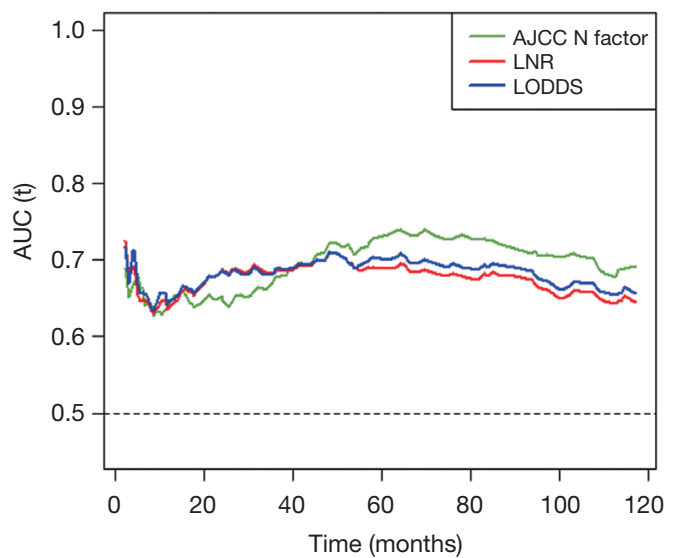

Figure 3 Time-dependent ROC curves for the AJCC N factor, LNR and LODDS in the group including all young gastric cancer patients (A) and the group of patients with $\leq 15$ examined lymph nodes (B). The horizontal axis represents the time after initial diagnosis and the vertical axis represents the estimated area under the ROC curve for survival at the time of interest. Green, red and blue solid lines represented the estimated AUCs of AJCC N factor, LNR and LODDS, respectively. LNR, lymph node ratio; LODDS, log odds of positive lymph nodes.

Table 3 Estimated AUC of AJCC N factor, LNR and LODDS for OS at 1, 3, 5 and 10 years in young patients with gastric cancer

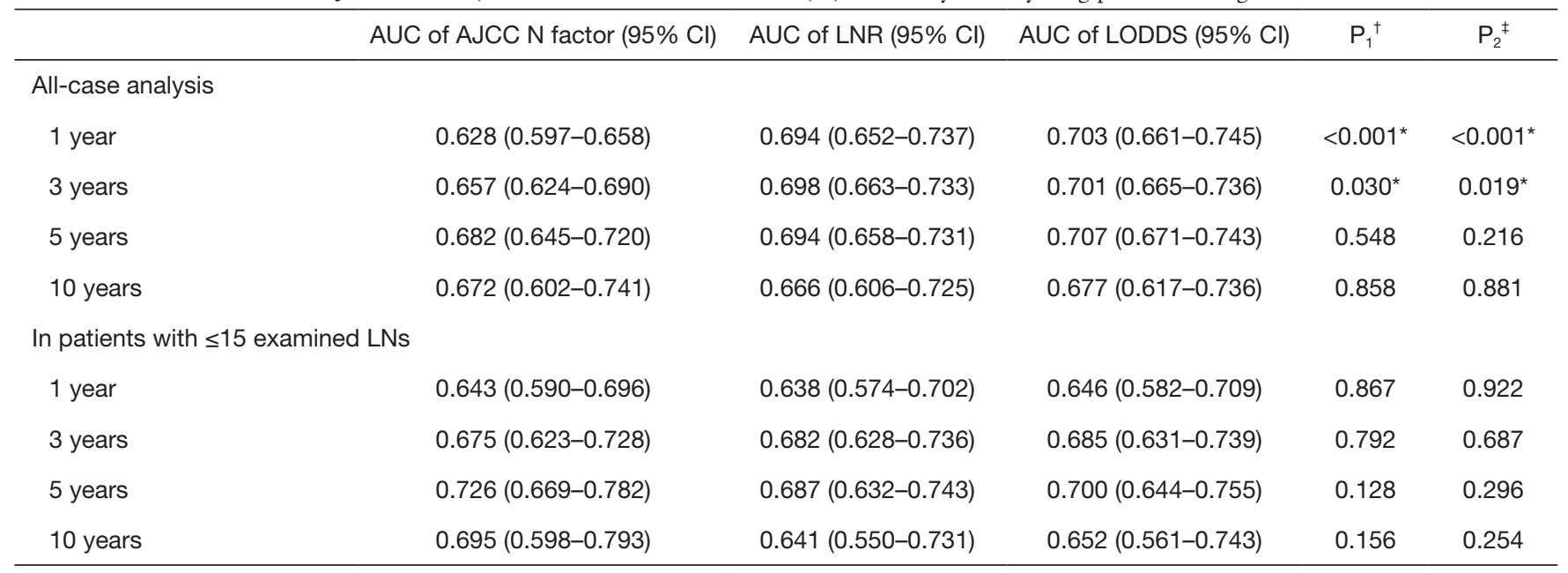

AUC, area under the curve; LNR, lymph node ratio; LODDS, the log odds of positive lymph nodes; Cl, confidence interval; LN, lymph node. ${ }^{*}$ indicate significant $\mathrm{P}$ values. ${ }^{\dagger}, \mathrm{P}_{1}$ value: AUC of AJCC $\mathrm{N}$ factor vs. AUC of LNR. ${ }^{\ddagger}, \mathrm{P}_{2}$ value: AUC of AJCC N factor vs. AUC of LODDS.

quantify the predictive accuracy of the AJCC N factor, LNR and LODDS, and to compare their sequential trends on hazard ratios for OS. In the group including all young GC patients, the time-dependent ROC curves of both the LNR and the LODDS were generally continuously superior to that of the $\mathrm{N}$ factor in predicting the survival (Figure $3 A$ ). Additionally, the AUCs generated for survival status at 1 and 3 years for the LNR and LODDS were significantly superior to that of the $\mathrm{N}$ factor (AUC values: LNR: 0.694 and 0.698,
LODDS: 0.703 and $0.701, \mathrm{~N}$ factor: 0.628 and 0.657 , respectively), with a statistical difference (at 1 year: LNR $v$. $\mathrm{N}$ factor: $\mathrm{P}<0.001$, LODDS $v$ s. $\mathrm{N}$ factor: $\mathrm{P}<0.001$; at 3 years: LNR vs. $\mathrm{N}$ factor: $\mathrm{P}=0.030$, LODDS vs. $\mathrm{N}$ factor: $\mathrm{P}=0.019$ ) (Table 3). However, at 5 and 10 years, the AUCs for the LNR were 0.694 and $0.666,0.707$ and 0.677 for the LODDS, 0.682 and 0.672 for the $\mathrm{N}$ factor, with $\mathrm{P}>0.05$ (Table 3), indicating that the predictive accuracy of these three LN staging methods at 5 and 10 years was comparable. 

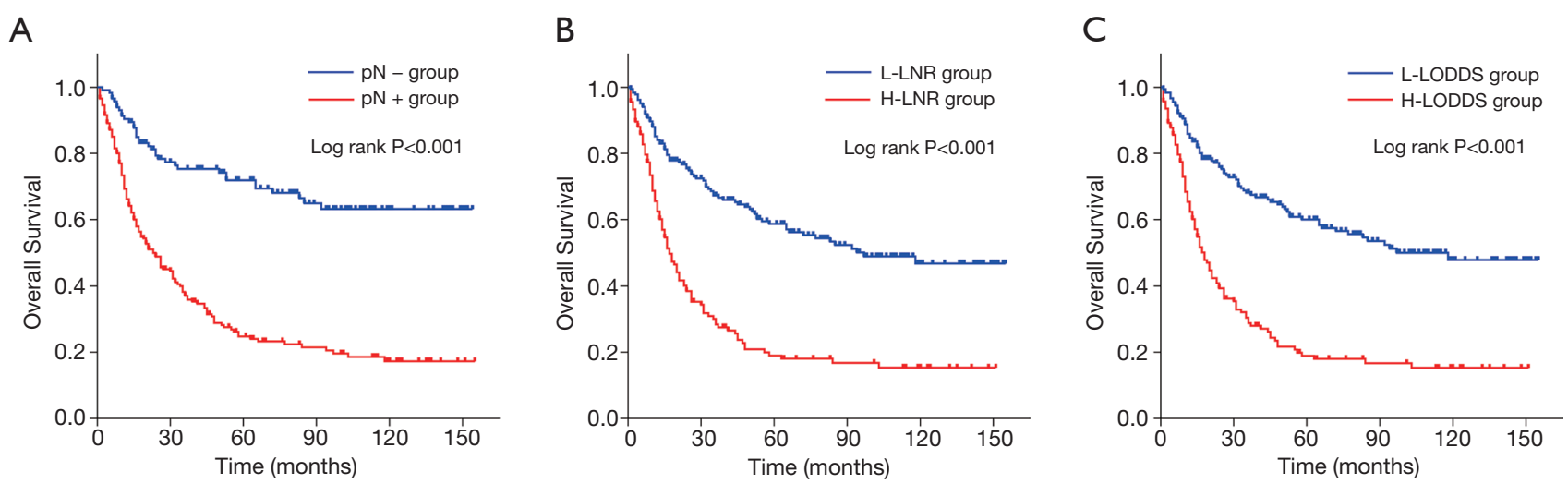

Figure 4 Kaplan-Meier analysis for overall survival of young gastric cancer patients with $\leq 15$ examined lymph nodes in the negative and positive lymph node metastasis groups (A), low and high lymph node ratio groups (B), and low and high log odds of positive lymph nodes groups (C). The AJCC N factor, LNR and LODDS were significantly associated with overall survival (all $\mathrm{P}<0.001)$. LNR, lymph node ratio; LODDS, $\log$ odds of positive lymph nodes.

\section{Comparisons among the three multivariate models}

The C-index, AIC and likelihood ratio $\chi^{2}$ scores were used to compare the distinguishing abilities of multivariate model 1 ( $\mathrm{T}$ stage, $\mathrm{N}$ factor and $\mathrm{M}$ stage), multivariate model 2 ( $\mathrm{T}$ stage, LNR and $M$ stage) and multivariate model 3 ( $T$ stage, LODDS and $M$ stage), and to identify a superior multivariate prediction model (Table 4). In an analysis including all young GC patients, the $\mathrm{C}$-index values in the model $2(0.783,95 \%$ CI: 0.759-0.806) and model 3 (0.783, 95\% CI: $0.760-0.807)$ significantly increased when comparing with the model 1 (0.774, 95\% CI: 0.749-0.799) (model 2 vs. model 1: $\mathrm{P}=0.042$, model 3 vs. model 1: $\mathrm{P}=0.034)$. Furthermore, the AIC values in the model 2 $(4,584.90)$ and model $3(4,582.39)$ were smaller than that in the model $1(4,614.48)$. These results indicated that incorporating the LNR or LODDS into the multivariate model could enable a superior prediction model for survival in young patients with GC.

\section{Overall survival in patients with 15 or fewer examined lymph nodes}

Kaplan-Meier curves of OS based on the $\mathrm{N}$ factor, LNR and LODDS in young GC patients with 15 or fewer examined LNs were shown in Figure 4. Three LN staging methods were significantly correlated with OS (all $\mathrm{P}<0.001$ ). In a multivariate analysis for OS, the AJCC $\mathrm{N}$ factor (HR $=1.690,95 \%$ CI: 1.115-2.562, P=0.013), LNR (HR $=1.424,95 \%$ CI: $1.019-1.990, \mathrm{P}=0.038$ ) and LODDS (HR $=1.397,95 \%$ CI: $1.002-1.949, \mathrm{P}=0.049)$ were significantly independent prognostic factors in these patients (Table S1). In the subgroup including patients with $\leq 15$ LNs examined, although the time-dependent ROC curve of the $\mathrm{N}$ factor was continuously superior to that of the LNR and LODDS in predicting the survival after 5 years (Figure 3B), the AUC values among these three $\mathrm{LN}$ staging methods were not statistically different $(\mathrm{P}>0.05)$ (Table 3).

In an analysis including the population of patients with $\leq 15 \mathrm{LNs}$ examined, the AIC values in the multivariate model 1,2 and 3 were $1,782.58,1,786.92$ and 1,786.36, respectively (Table 4). The C-index in the model 1, 2 and 3 were 0.787 (95\% CI: 0.752-0.822), 0.784 (95\% CI: 0.749 0.820 ) and 0.0 .785 (95\% CI: $0.749-0.820)$, respectively. The multivariate model 1 had a slightly increased C-index, but no significant differences were found when comparing to the model 2 and 3 (model 2 vs. model 1: $\mathrm{P}=0.331$, model 3 vs. model 1: $\mathrm{P}=0.354)$.

\section{Discussion}

Recently, several lines of findings have reported an increasing trend in the incidence of GC patients in young age $(2,3,13,45)$. GC in the young has a more aggressive growth pattern and carries a worse clinical outcome compared with older individuals (6,9,20-22). An effective and well practical prediction model is urgently required for prognosis estimation and guidance in such separate entity. AJCC TNM staging is the most widely reliable and accepted system in GC, but it is subject to the risk of stage migration when using the $\mathrm{N}$ classification. Accurate staging 
Table 4 Comparison of different prognostic models on young patients with gastric cancer

\begin{tabular}{|c|c|c|c|c|c|}
\hline & \multicolumn{3}{|c|}{ Concordance indices } & $\mathrm{AIC}$ & Likelihood Ratio $\chi^{2}$ \\
\hline \multicolumn{6}{|c|}{ All-case analysis } \\
\hline Model $1^{\dagger}$ & 0.774 & $0.749-0.799$ & & $4,614.48$ & 291 \\
\hline Model $2^{\ddagger}$ & 0.783 & $0.759-0.806$ & $0.042^{*}$ & $4,584.90$ & 320.6 \\
\hline \multicolumn{6}{|c|}{ In patients with $\leq 15$ examined LNs } \\
\hline Model $1^{\dagger}$ & 0.787 & $0.752-0.822$ & & $1,782.58$ & 154.8 \\
\hline Model $2^{\ddagger}$ & 0.784 & $0.749-0.820$ & 0.331 & $1,786.92$ & 150.4 \\
\hline Model $3^{\S}$ & 0.785 & $0.749-0.820$ & 0.354 & $1,786.36$ & 151 \\
\hline
\end{tabular}

$\mathrm{Cl}$, confidence interval; LN, lymph node. *, indicate significant $\mathrm{P}$ values. ${ }^{\dagger}$, Model 1: T stage, AJCC N factor, $\mathrm{M}$ stage. ${ }^{\ddagger}$, Model 2: T stage, LNR, M stage. ${ }^{\S}$, Model 3: T stage, LODDS, M stage.

plays a pivotal role in cancer care. In the present study, we evaluated the prognostic abilities of the three LN staging systems including AJCC $\mathrm{N}$ factor, LNR and LODDS in young patients with GC. To our knowledge, no study before has compared the predictive value of the ratio-based nodal staging, LNR and LODDS, with the number-based $\mathrm{N}$ category in such special population. We demonstrated that the ratio-based nodal staging, LNR and LODDS, were remarkable prognosticators for survival in the young GC patients and in the population of patients with $\leq 15$ LNs examined. Although AJCC $\mathrm{N}$ factor was also an independent risk factor in our study cohort, it was observed a significant correlation when patients were divided into two subgroups according to whether total LNs examined $\leq 15$ or not, and might lead to stage migration. Additionally, the multivariate prediction models incorporating the LNR or LODDS had higher C-index and lower AIC when comparing to the model incorporating the $\mathrm{N}$ factor, suggesting uses of LNR and LODDS as alternatives to the $\mathrm{N}$ factor for the prognostic prediction of young patients with GC.

Lymph node metastasis is the most frequent mode of tumor metastasis in GC, and thus lymph node dissection plays a crucial role in GC surgery for staging and treatment options $(26,46)$. The pathological assessment of LNs in the 8th edition of AJCC TNM staging system is on the basis of the absolute count of positive LNs, and its predictive efficacy for prognosis is significantly influenced by the extent of LN dissection (28-31,47). A study from Smith et al. using SEER data between 1973 and 1999 found a therapeutic benefit of a large number of examined LNs (30). According to the TNM staging, at least 15 harvested LNs is essential for accurate estimates of $\mathrm{N}$ category. A poor primary LN count could produce stage migration, compromise a correct staging and subsequently underestimate the severity of disease $(28,29,31,48) .10-15 \%$ of patients were found the phenomenon of stage migration when using the $\mathrm{N}$ classification $(29-32,38)$. To reduce the potential bias caused by an insufficient number of harvested LNs and stage migration, the LNR, namely, the ratio between positive and examined LNs, has been proposed for ameliorating the understaging of diagnosis and more accurately assessing the disease severity. The LNR is less influenced by the total number of harvested LNs. Extensive studies have reported that the LNR, rather than the existing AJCC N staging, could compensate for the stage migration effect and had a better predictive value in GC patients, suggesting it to be considered as an alternative to the $\mathrm{N}$ classification in patients with adequate or inadequate $\mathrm{LNs}$ examined (33-39,49,50). However, the LNR also has its flaws in failing to stratify the prognosis of patients with no metastatic $(\mathrm{LNR}=0)$ or all metastatic $(\mathrm{LNR}=1) \mathrm{LNs}$. These flaws contributed to the creation of the LODDS, which is defined as the $\log$ value of the ratio between positive nodes and negative nodes $(40,41)$. The LODDS, using a base number and negative nodes as the denominator, carries all the auxiliary information of the LNR, and therefore it could further distinguish those patients with either very high or low LNR. Spolverato et al. observed that when the LN status was modeled as a continuous variable, the 
LODDS was the best predictor of survival (51). However, the LODDS might lost its predictive value and the LNR became the best predictor when the LN status was categorized.

In the present study, we found that the three different LN staging methods, AJCC N factor, LNR and LODDS, were significantly independent prognostic factors for OS in the cohort including all young GC patients and in the subgroups comprised of patients with $\leq 15$ LNs examined. However, correlation analysis between clinicopathological characteristics and there different LN staging methods observed a significant correlation in the AJCC $\mathrm{N}$ factor $(\mathrm{P}<0.001)$ when patients were divided into two subgroups according to whether total LNs examined $\leq 15$ or not, indicating that there might exist stage migration. Moreover, the time-dependent ROC curves of the LNR and LODDS were continuously superior to that of the $\mathrm{N}$ factor in predicting OS during the observation period. And the AUCs also revealed that the predictive accuracy of the LNR and LODDS was remarkably superior to the $\mathrm{N}$ factor at 1 and 3 years. In addition, the multivariate models incorporating the LNR or LODDS had higher C-index values and lower AIC values when comparing to the model incorporating the $\mathrm{N}$ factor, suggesting that the LNR and LODDS could be considered as alternatives to the $\mathrm{N}$ factor for prognostic prediction in young patients with GC. In patients with $\leq 15$ examined nodes, the prognostic power of the three LN classification methods was comparable.

Although the present study enabled us to distinguish a better LN staging method for predicting prognosis of young GC patients, we did not investigate the effect of neoadjuvant therapy on the nodal status. Currently, in the west, it is recommended that GC be treated in a multimodal fashion and surgical treatment should be preceded by neoadjuvant (perioperative) chemotherapy. An analysis of pathologic tumor response and nodal status in the Perioperative Chemotherapy versus Surgery Alone for Resectable Gastroesophageal Cancer (MAGIC) trial demonstrated that neoadjuvant chemotherapy with a regimen of epirubicin, cisplatin, and fluorouracil decreased tumor size and stage and significantly improved survival (52). Moreover, a recent study based on the MAGIC trial found that the LN metastases and not the regression of the primary tumor was the primary arbiter of survival after chemotherapy plus resection (53). Tumor diameter and depth of infiltration, Lauren histological subtype, and tumor regression grading may reflect the impact of neoadjuvant therapy on LN status (54). A study from Roland et al. focus on the effect of neoadjuvant therapy on the LNR in pancreatic cancer and showed that the LNR might serve as a better prognostic parameter following neoadjuvant therapy than standard N0 or N1 annotation (55). Similarly, neoadjuvant therapy in rectal cancer did not affect LNR despite reduced LN retrieval and therefore LNR might be a more reliable prognosticator than $\mathrm{LN}$ retrieval (56). In this study, patients who received neoadjuvant therapy/ radiotherapy were excluded from the analysis. Even though our study's most noticeable findings shed light on clinical advantage of the LNR and LODDS over the $\mathrm{N}$ classification in young patients with GC, the results may not be applicable to all patients, especially those with resectable GC undergoing neoadjuvant therapy.

This study has several limitations. Firstly, this study was retrospective and potential bias might have led to in the data selection process. Secondly, it was a population-based study capturing data from national registry, but the detailed information on therapy and outcomes were limited in the SEER database. Apart from OS, other clinical outcomes such as quality of life, distant control, local control were not recorded. Information about type of gastrectomy, systemic therapy, specialized regimens and measurement of response to treatment were also absent, which could influence the detailed real-world outcomes for young patients with GC and the prognostic power of the LNR and LODDS to some extent. Thirdly, there was no consensus regarding the cutoffs for the LNR and LODDS even though different cutoff values had been proposed. Here we determined the LNR and LODDS cutoffs of 0.36 and -0.28 , respectively, and found the LNR and LODDS to be the independent prognostic factors. The results of this study may not be appropriate for other studies. The most optimal cutoffs for young patients with GC should be further investigated. Finally, we did not verify the results in our own patients. Further external validation such as enrolling our own patients is warranted to extend the extrapolation of the reported results. And additional prospective multicenter studies are also necessary.

Despite these limitations, the present study also has many strengths. To our knowledge, it is the first comparing the predictive value of the ratio-based nodal staging, LNR and LODDS, and the number-based $\mathrm{N}$ classification in young patients with GC, such a special population. The findings of our study are intuitive, convenient to use and well-timed. An accurate staging is indeed of great significance for determining the suitable therapeutic schedule and follow-up scheme for every stage of the disease. Even though the current AJCC 
TNM staging is the most widely used system, it also has its deficiency especially in the population of patients with an insufficient number of harvested LNs. Findings from our study detected clinical advantage of the LNR and LODDS over the $\mathrm{N}$ classification. These results may be regarded as a basis for prospective researches and affect the clinical treatment options for young patients with GC.

\section{Conclusions}

In conclusion, the current study demonstrated that the LNR and LODDS were significant independent prognostic indicators for OS in young patients with GC. The predictive performance of the LNR and LODDS were superior to that of the AJCC N factor, suggesting that the LNR and LODDS could improve accuracy of survival risk prediction and should be considered as alternatives to the AJCC $\mathrm{N}$ factor for the prognostic prediction of young patients with GC.

\section{Acknowledgments}

We thank all staff of the SEER program for the creation of the SEER database.

Funding: This study was supported by Guangzhou Science and Technology Development Funds (Key Program, No. 201803010103).

\section{Footnote}

Reporting Checklist: The authors have completed the STROBE reporting checklist. Available at https://dx.doi. org/10.21037/jgo-21-185

Conflicts of Interest: All authors have completed the ICMJE uniform disclosure form (available at https://dx.doi. org/10.21037/jgo-21-185). The authors have no conflicts of interest to declare.

Ethical Statement: The authors are accountable for all aspects of the work in ensuring that questions related to the accuracy or integrity of any part of the work are appropriately investigated and resolved. The SEER database is an open-access cancer database that only contains deidentified patient data. Therefore, this study was exempted from the approval by the institutional review board of the First Affiliated Hospital of Sun Yat-sen University. The study was conducted in accordance with the Declaration of
Helsinki (as revised in 2013).

Open Access Statement: This is an Open Access article distributed in accordance with the Creative Commons Attribution-NonCommercial-NoDerivs 4.0 International License (CC BY-NC-ND 4.0), which permits the noncommercial replication and distribution of the article with the strict proviso that no changes or edits are made and the original work is properly cited (including links to both the formal publication through the relevant DOI and the license). See: https://creativecommons.org/licenses/by-nc-nd/4.0/.

\section{References}

1. Sung H, Ferlay J, Siegel RL, et al. Global Cancer Statistics 2020: GLOBOCAN Estimates of Incidence and Mortality Worldwide for 36 Cancers in 185 Countries. CA Cancer J Clin 2021;71:209-49.

2. Fidler MM, Gupta S, Soerjomataram I, et al. Cancer incidence and mortality among young adults aged 20-39 years worldwide in 2012: a population-based study. Lancet Oncol 2017;18:1579-89.

3. Islami F, DeSantis CE, Jemal A. Incidence Trends of Esophageal and Gastric Cancer Subtypes by Race, Ethnicity, and Age in the United States, 1997-2014. Clin Gastroenterol Hepatol 2019;17:429-39.

4. Isobe T, Hashimoto K, Kizaki J, et al. Characteristics and prognosis of gastric cancer in young patients. Oncol Rep 2013;30:43-9.

5. Liu S, Feng F, Xu G, et al. Clinicopathological features and prognosis of gastric cancer in young patients. BMC Cancer 2016;16:478.

6. Takatsu Y, Hiki N, Nunobe S, et al. Clinicopathological features of gastric cancer in young patients. Gastric Cancer 2016;19:472-8.

7. Lee J, Lee MA, Kim IH, et al. Clinical characteristics of young-age onset gastric cancer in Korea. BMC Gastroenterol 2016;16:110.

8. Chung HW, Noh SH, Lim JB. Analysis of demographic characteristics in 3242 young age gastric cancer patients in Korea. World J Gastroenterol 2010;16:256-63.

9. Al-Refaie WB, Hu CY, Pisters PW, et al. Gastric adenocarcinoma in young patients: a population-based appraisal. Ann Surg Oncol 2011;18:2800-7.

10. Santoro R, Carboni F, Lepiane P, et al. Clinicopathological features and prognosis of gastric cancer in young European adults. Br J Surg 2007;94:737-42.

11. López-Basave HN, Morales-Vásquez F, Ruiz-Molina JM, 
et al. Gastric cancer in young people under 30 years of age: worse prognosis, or delay in diagnosis? Cancer Manag Res 2013;5:31-6.

12. Park HJ, Ahn JY, Jung HY, et al. Clinical characteristics and outcomes for gastric cancer patients aged 18-30 years. Gastric Cancer 2014;17:649-60.

13. Merchant SJ, Kim J, Choi AH, et al. A rising trend in the incidence of advanced gastric cancer in young Hispanic men. Gastric Cancer 2017;20:226-34.

14. Pisanu A, Podda M, Cois A, et al. Gastric cancer in the young: is it a different clinical entity? A retrospective cohort study. Gastroenterol Res Pract 2014;2014:125038.

15. Suh DD, Oh ST, Yook JH, et al. Differences in the prognosis of early gastric cancer according to sex and age. Therap Adv Gastroenterol 2017;10:219-29.

16. Nelen SD, Verhoeven RHA, Lemmens VEPP, et al. Increasing survival gap between young and elderly gastric cancer patients. Gastric Cancer 2017;20:919-28.

17. Smith AW, Bellizzi KM, Keegan TH, et al. Health-related quality of life of adolescent and young adult patients with cancer in the United States: the Adolescent and Young Adult Health Outcomes and Patient Experience study. J Clin Oncol 2013;31:2136-45.

18. De B, Rhome R, Jairam V, et al. Gastric adenocarcinoma in young adult patients: patterns of care and survival in the United States. Gastric Cancer 2018;21:889-99.

19. Carvalho R, Milne AN, van Rees BP, et al. Early-onset gastric carcinomas display molecular characteristics distinct from gastric carcinomas occurring at a later age. J Pathol 2004;204:75-83.

20. Hsieh FJ, Wang YC, Hsu JT, et al. Clinicopathological features and prognostic factors of gastric cancer patients aged 40 years or younger. J Surg Oncol 2012;105:304-9.

21. Koea JB, Karpeh MS, Brennan MF. Gastric cancer in young patients: demographic, clinicopathological, and prognostic factors in 92 patients. Ann Surg Oncol 2000;7:346-51.

22. Rona KA, Schwameis K, Zehetner J, et al. Gastric cancer in the young: An advanced disease with poor prognostic features. J Surg Oncol 2017;115:371-5.

23. Treadgold CL, Kuperberg A. Been there, done that, wrote the blog: the choices and challenges of supporting adolescents and young adults with cancer. J Clin Oncol 2010;28:4842-9.

24. Thomas DM, Albritton KH, Ferrari A. Adolescent and young adult oncology: an emerging field. J Clin Oncol 2010;28:4781-2.

25. Sano T, Coit DG, Kim HH, et al. Proposal of a new stage grouping of gastric cancer for TNM classification: International Gastric Cancer Association staging project. Gastric Cancer 2017;20:217-25.

26. Amin MB, Edge SB, Greene FL, et al., editors. AJCC cancer staging manual. 8th ed. New York: Springer; 2017.

27. In H, Solsky I, Palis B, et al. Validation of the 8 th edition of the AJCC TNM staging system for gastric cancer using the National Cancer Database. Ann Surg Oncol 2017;24:368391.

28. Lee HK, Yang HK, Kim WH, et al. Influence of the number of lymph nodes examined on staging of gastric cancer. Br J Surg 2001;88:1408-12.

29. de Manzoni G, Verlato G, Roviello F, et al. The new TNM classification of lymph node metastasis minimises stage migration problems in gastric cancer patients. $\mathrm{Br} \mathrm{J}$ Cancer 2002;87:171-4.

30. Smith DD, Schwarz RR, Schwarz RE. Impact of total lymph node count on staging and survival after gastrectomy for gastric cancer: data from a large USpopulation database. J Clin Oncol 2005;23:7114-24.

31. Bunt AM, Hermans J, Smit VT, et al. Surgical/pathologicstage migration confounds comparisons of gastric cancer survival rates between Japan and Western countries. J Clin Oncol 1995;13:19-25.

32. Feinstein AR, Sosin DM, Wells CK. The Will Rogers phenomenon. Stage migration and new diagnostic techniques as a source of misleading statistics for survival in cancer. N Engl J Med 1985;312:1604-8.

33. Agnes A, Biondi A, Cananzi FM, et al. Ratio-based staging systems are better than the 7 th and 8 th editions of the TNM in stratifying the prognosis of gastric cancer patients: a multicenter retrospective study. J Surg Oncol 2019;119:948-57.

34. Kong SH, Lee HJ, Ahn HS, et al. Stage migration effect on survival in gastric cancer surgery with extended lymphadenectomy: the reappraisal of positive lymph node ratio as a proper N-staging. Ann Surg 2012;255:50-8.

35. Marchet A, Mocellin S, Ambrosi A, et al. The ratio between metastatic and examined lymph nodes ( $\mathrm{N}$ ratio) is an independent prognostic factor in gastric cancer regardless of the type of lymphadenectomy: results from an Italian multicentric study in 1853 patients. Ann Surg 2007;245:543-52.

36. Maduekwe UN, Lauwers GY, Fernandez-Del-Castillo C, et al. New metastatic lymph node ratio system reduces stage migration in patients undergoing D1 lymphadenectomy for gastric adenocarcinoma. Ann Surg Oncol 2010;17:1267-77. 
37. Rodríguez Santiago JM, Muñoz E, Martí M, et al. Metastatic lymph node ratio as a prognostic factor in gastric cancer. Eur J Surg Oncol 2005;31:59-66.

38. Bando E, Yonemura Y, Taniguchi K, et al. Outcome of ratio of lymph node metastasis in gastric carcinoma. Ann Surg Oncol 2002;9:775-84.

39. Xu DZ, Geng QR, Long ZJ, et al. Positive lymph node ratio is an independent prognostic factor in gastric cancer after $\mathrm{d} 2$ resection regardless of the examined number of lymph nodes. Ann Surg Oncol 2009;16:319-26.

40. Sun Z, Xu Y, Li de M, et al. Log odds of positive lymph nodes: a novel prognostic indicator superior to the number-based and the ratio-based $\mathrm{N}$ category for gastric cancer patients with $\mathrm{R} 0$ resection. Cancer 2010;116:2571-80.

41. Qiu MZ, Qiu HJ, Wang ZQ, et al. The tumor-log odds of positive lymph nodes-metastasis staging system, a promising new staging system for gastric cancer after D2 resection in China. PLoS One 2012;7:e31736.

42. Camp RL, Dolled-Filhart M, Rimm DL. X-tile: a new bio-informatics tool for biomarker assessment and outcome-based cut-point optimization. Clin Cancer Res 2004;10:7252-9.

43. Heagerty PJ, Lumley T, Pepe MS. Time-dependent ROC curves for censored survival data and a diagnostic marker. Biometrics 2000;56:337-44.

44. Rodríguez-Álvarez MX, Meira-Machado L, Abu-Assi E, et al. Nonparametric estimation of time-dependent ROC curves conditional on a continuous covariate. Stat Med 2016;35:1090-102.

45. Jiang $\mathrm{Y}$, Huang $\mathrm{W}$, Xie J, et al. Young age increases risk for lymph node positivity in gastric cancer: A Chinese multiinstitutional database and US SEER database study. J Cancer 2020;11:678-85.

46. Dicken BJ, Bigam DL, Cass C, et al. Gastric adenocarcinoma: review and considerations for future directions. Ann Surg 2005;241:27-39.

47. Wu CW, Hsiung CA, Lo SS, et al. Nodal dissection for

Cite this article as: Chen YR, Wang MQ, Li YT, Li P, Ouyang SS, Xu HW, Zhu SL. Prognostic performance of different lymph node classification systems in young gastric cancer. J Gastrointest Oncol 2021;12(4):1285-1300. doi: 10.21037/jgo-21185 patients with gastric cancer: a randomised controlled trial. Lancet Oncol 2006;7:309-15.

48. Kim CY, Yang DH. Adjustment of $\mathrm{N}$ stages of gastric cancer by the ratio between the metastatic and examined lymph nodes. Ann Surg Oncol 2009;16:1868-74.

49. Lee JH, Kang JW, Nam BH, et al. Correlation between lymph node count and survival and a reappraisal of lymph node ratio as a predictor of survival in gastric cancer: A multi-institutional cohort study. Eur J Surg Oncol 2017;43:432-9.

50. Kulig J, Sierzega M, Kolodziejczyk P, et al. Ratio of metastatic to resected lymph nodes for prediction of survival in patients with inadequately staged gastric cancer. Br J Surg 2009;96:910-8.

51. Spolverato G, Ejaz A, Kim Y, et al. Prognostic Performance of Different Lymph Node Staging Systems After Curative Intent Resection for Gastric Adenocarcinoma. Ann Surg 2015;262:991-8.

52. Cunningham D, Allum WH, Stenning SP, et al. Perioperative chemotherapy versus surgery alone for resectable gastroesophageal cancer. N Engl J Med 2006;355:11-20.

53. Smyth EC, Fassan M, Cunningham D, et al. Effect of Pathologic Tumor Response and Nodal Status on Survival in the Medical Research Council Adjuvant Gastric Infusional Chemotherapy Trial. J Clin Oncol 2016;34:2721-7.

54. Rawicz-Pruszyński K, Ciseł B, Mlak R, et al. The Role of the Lymph Node Ratio in Advanced Gastric Cancer After Neoadjuvant Chemotherapy. Cancers (Basel) 2019;11:1914.

55. Roland CL, Yang AD, Katz MH, et al. Neoadjuvant therapy is associated with a reduced lymph node ratio in patients with potentially resectable pancreatic cancer. Ann Surg Oncol 2015;22:1168-75.

56. Chang KH, Kelly NP, Duff GP, et al. Neoadjuvant therapy does not affect lymph node ratio in rectal cancer. Surgeon 2016;14:270-3. 


\section{Supplementary}

Table S1 Univariate and multivariate Cox proportional hazards regression analyses for OS in patients with $\leq 15$ examined LNs

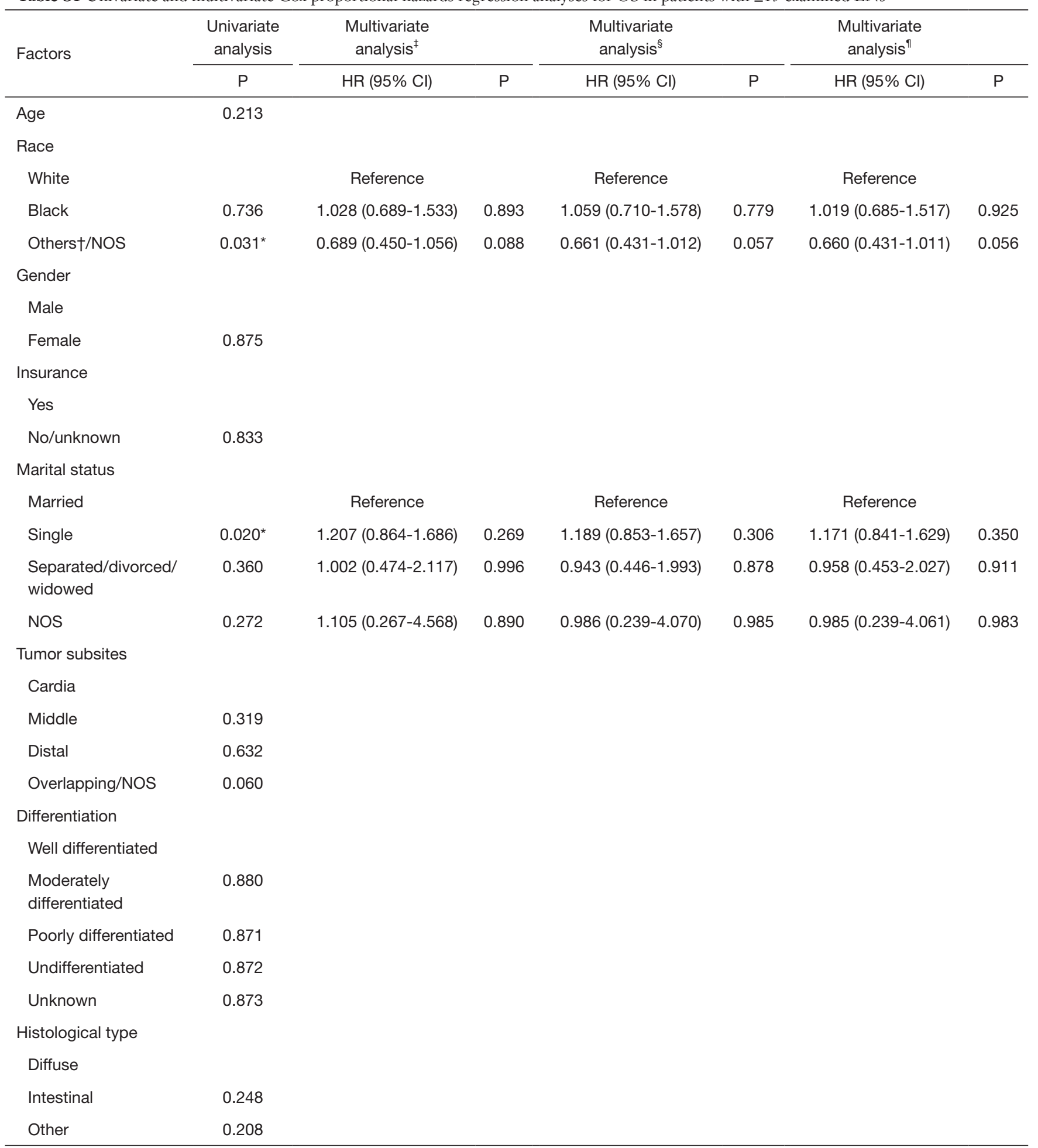

Table S1 (continued) 
Table S1 (continued)

\begin{tabular}{|c|c|c|c|c|c|c|c|}
\hline \multirow[t]{2}{*}{ Factors } & \multirow{2}{*}{$\begin{array}{c}\begin{array}{c}\text { Univariate } \\
\text { analysis }\end{array} \\
\mathrm{P}\end{array}$} & \multicolumn{2}{|l|}{$\begin{array}{c}\text { Multivariate } \\
\text { analysis }^{\ddagger}\end{array}$} & \multicolumn{2}{|l|}{$\begin{array}{c}\text { Multivariate } \\
\text { analysis }^{\S}\end{array}$} & \multicolumn{2}{|l|}{$\begin{array}{c}\text { Multivariate } \\
\text { analysis }\end{array}$} \\
\hline & & $\mathrm{HR}(95 \% \mathrm{Cl})$ & $\mathrm{P}$ & $\mathrm{HR}(95 \% \mathrm{Cl})$ & $\mathrm{P}$ & $\mathrm{HR}(95 \% \mathrm{Cl})$ & $\mathrm{P}$ \\
\hline$<1 \mathrm{~cm}$ & & Reference & & Reference & & Reference & \\
\hline $1-2 \mathrm{~cm}$ & 0.248 & $0.875(0.172-4.458)$ & 0.872 & $1.095(0.221-5.436)$ & 0.911 & $1.088(0.219-5.397)$ & 0.918 \\
\hline $3-4 \mathrm{~cm}$ & $0.012^{*}$ & $0.534(0.108-2.641)$ & 0.442 & $0.621(0.129-2.975)$ & 0.551 & $0.625(0.131-2.992)$ & 0.556 \\
\hline $4-5 \mathrm{~cm}$ & $0.004^{*}$ & $0.627(0.125-3.138)$ & 0.570 & $0.702(0.144-3.414)$ & 0.661 & $0.692(0.142-3.368)$ & 0.648 \\
\hline$\geq 5 \mathrm{~cm}$ & $0.001^{*}$ & $0.958(0.203-4.518)$ & 0.956 & $1.117(0.245-5.099)$ & 0.887 & $1.113(0.244-5.082)$ & 0.890 \\
\hline NOS & $0.004^{*}$ & $0.822(0.171-3.960)$ & 0.807 & $0.929(0.198-4.360)$ & 0.926 & $0.931(0.199-4.363)$ & 0.928 \\
\hline $\mathrm{T} 2$ & $<0.001^{*}$ & $15.734(4.902-50.505)$ & $<0.001^{*}$ & $17.395(5.502-55.002)$ & $<0.001^{*}$ & $17.369(5.500-54.851)$ & $<0.001^{\star}$ \\
\hline $\mathrm{T} 3$ & $<0.001^{*}$ & $21.727(6.506-72.561)$ & $<0.001^{\star}$ & 25.425 (7.735-83.569) & $<0.001^{*}$ & 24.938 (7.588-81.953) & $<0.001^{*}$ \\
\hline $\mathrm{T} 4$ & $<0.001^{*}$ & 29.855 (9.074-98.231) & $<0.001^{*}$ & $35.322(10.919-114.263)$ & $<0.001^{*}$ & $34.710(10.731-112.273)$ & $<0.001^{\star}$ \\
\hline TX & $<0.001^{*}$ & $56.596(8.666-369.611)$ & $0.001^{*}$ & 64.547 (9.979-417.502) & $<0.001^{*}$ & $62.456(9.639-404.673)$ & $<0.001^{*}$ \\
\hline
\end{tabular}

AJCC N factor

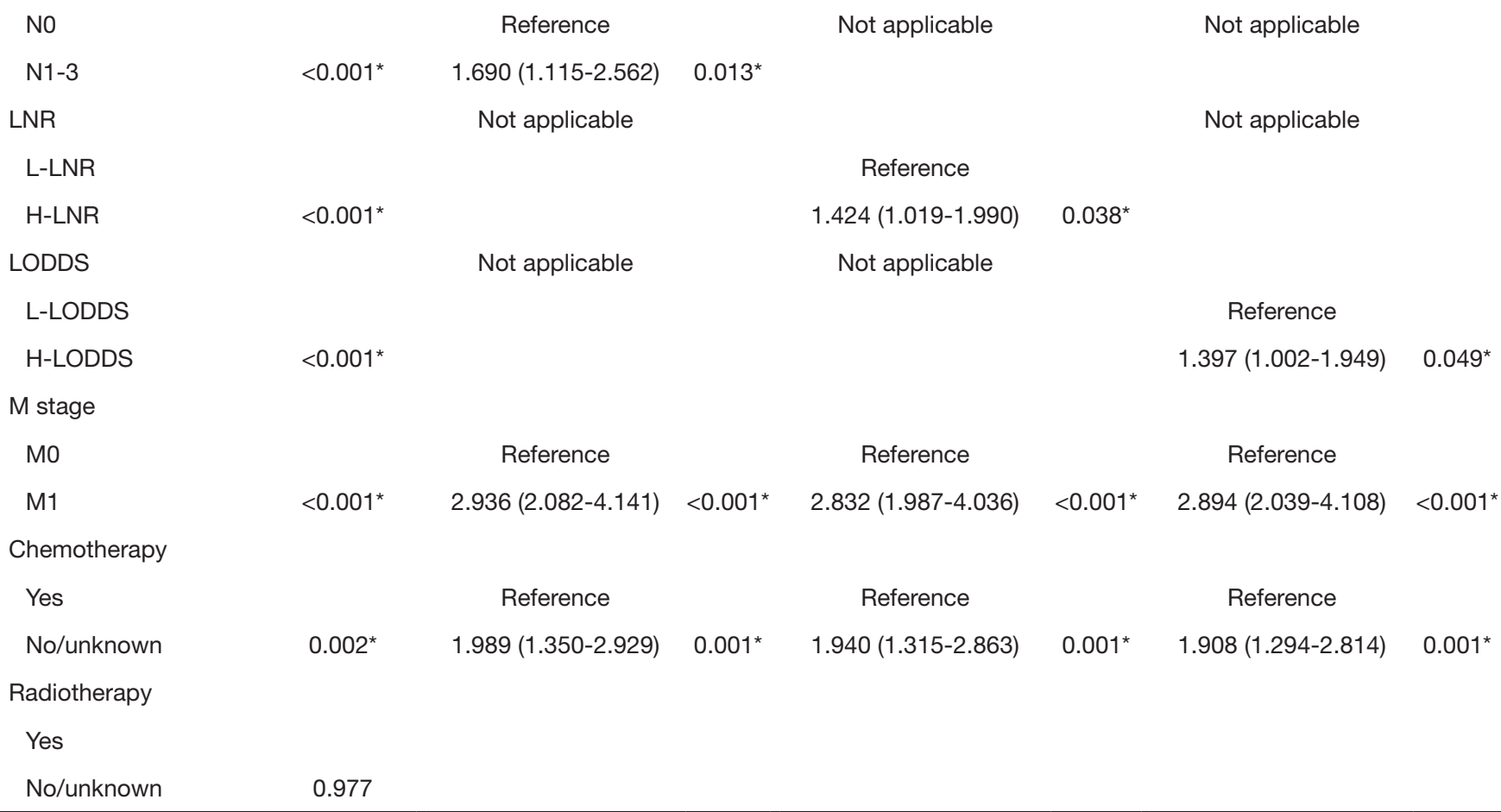

LNR, lymph node ratio; LODDS, the log odds of positive lymph nodes; NOS, not otherwise specified; HR, hazard ratio; Cl, confidence interval; LN, lymph nodes. ${ }^{*}$ indicate significant $\mathrm{P}$ values. ${ }^{\dagger}$ Others, American Indian/AK Native, Asian/Pacific Islander. ${ }^{\ddagger}$ Adjustment for the following variables: race, tumor subsites, tumor size, T stage, $\mathrm{N}$ stage, M stage, and chemotherapy. ${ }^{\S}$ Adjustment for the following variables: race, tumor subsites, tumor size, T stage, LNR, M stage, and chemotherapy. " Adjustment for the following variables: race, tumor subsites, tumor size, T stage, LODDS, M stage, and chemotherapy. 